\title{
Factors influencing healthcare service quality
}

\author{
Ali Mohammad Mosadeghrad*
}

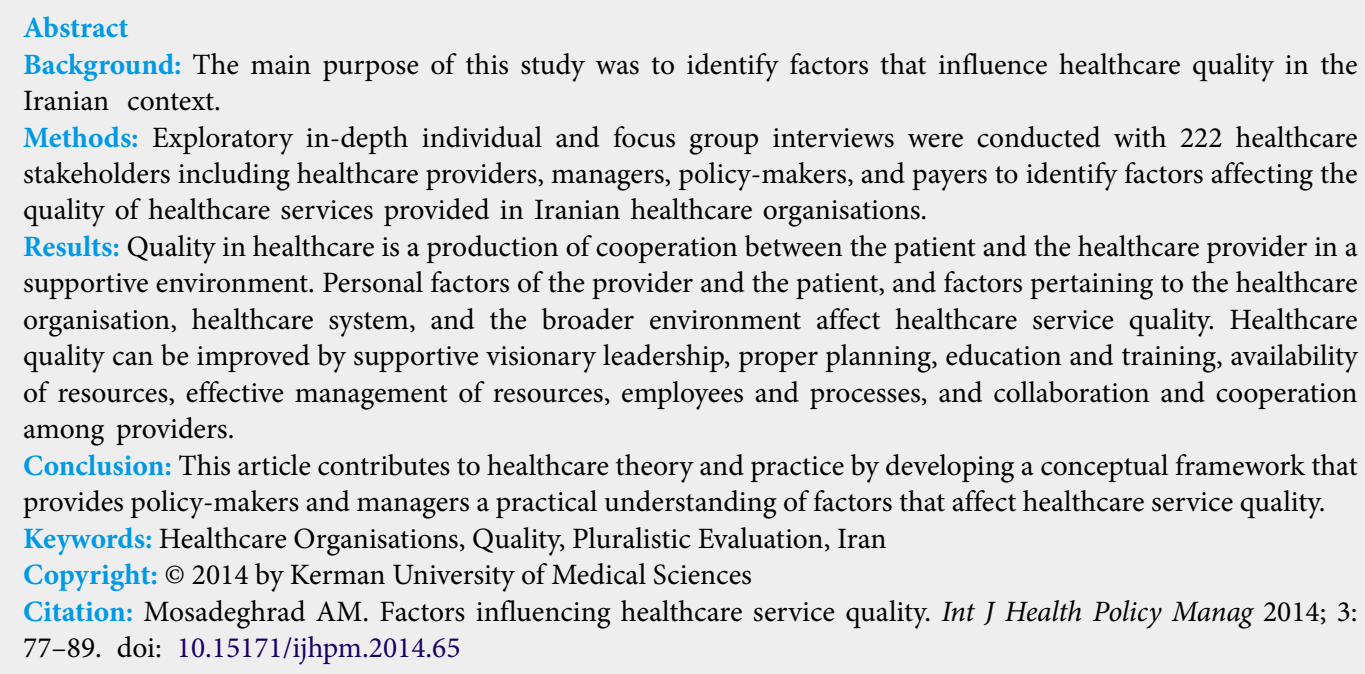
organisation, healthcare system, and the broader environment affect healthcare service quality. Healthcare quality can be improved by supportive visionary leadership, proper planning, education and training, availability of resources, effective management of resources, employees and processes, and collaboration and cooperation among providers.

Conclusion: This article contributes to healthcare theory and practice by developing a conceptual framework that provides policy-makers and managers a practical understanding of factors that affect healthcare service quality.

Keywords: Healthcare Organisations, Quality, Pluralistic Evaluation, Iran

Copyright: @ 2014 by Kerman University of Medical Sciences

Citation: Mosadeghrad AM. Factors influencing healthcare service quality. Int J Health Policy Manag 2014; 3 : 77-89. doi: 10.15171/ijhpm.2014.65

Article History:

Received: 26 April 2014 Accepted: 21 July 2014 ePublished: 26 July 2014

\section{Introduction}

The Iranian healthcare system has been characterised by a strong public sector component. Public healthcare services are complemented by the private sector (i.e. private hospitals and independent medical practitioners' clinics). The healthcare delivery system is structured into three levels. In the first level, Ministry of Health and Medical Education (MoHME) delivers free of charge Primary Healthcare (PHC) services. This level includes rural health houses, rural health centres, urban health posts, and urban health centres. The second level of the system consists of district health centres and district hospitals. The district health centre is responsible for the planning, supervision, and support of the PHC network. The third level of the system consists of the provincial health centres and specialty hospitals (1).

All formal workers and their dependents are insured by Social Security Organization (SSO). They receive healthcare services free of charge in SSO facilities. Members of the military forces and their dependents are covered through the Armed Forces Medical Service Organisation (AFMSO). The rest of the population is eligible to enroll in Medical Services Insurance Organization (MSIO), which has four funds covering government employees, rural households, the self-employed, and "others" (e.g. students). The MSIO is compulsory for the government employees and voluntary for the other groups. In addition, charity healthcare institutions focus mainly on providing outpatient services for the poor and healthcare institutions affiliated with the ministries of welfare, oil, and defense provide secondary and tertiary care, mainly to their employees (2).
The health status of Iranians has improved over the last two decades. Approximately $90 \%$ of the population has formal health insurance coverage (3). Up to $90 \%$ of the rural population and almost the entire urban population have adequate access to PHC services. As a result, child and maternal mortality rates have fallen significantly, and life expectancy at birth has risen remarkably. Life expectancy at birth increased to 73 years of age. With respect to health indicators, $95 \%$ of the population has access to safe drinking water. Additionally, 99\% of children reaching their first birthday are fully immunised. The crude birth and death rates are 16.8 and 5.3 per 1,000 respectively. The total fertility rate is 1.6 per woman. The maternal mortality ratio is 21 per 10,000 births (4). Despite these achievements, Iran's healthcare system faces a number of serious challenges, particularly concerning health outcomes, i.e. quality and efficiency (5-8). A full understanding of the concept of quality and the variables influencing healthcare services quality is needed to improve healthcare services quality.

\section{Literature review}

Quality has become an increasingly predominant part of our lives. People are constantly looking for quality products and services. The existence of this desire for quality has caused firms and organisations throughout the world to consider it as an essential component of any service and production process. Quality is a strategic differentiator tool for sustaining competitive advantage. Improving quality through improving structures and processes leads to a reduction of waste, rework, and delays, lower costs, higher market share, and a 
positive company image $(9,10)$. As a result, productivity and profitability improve (11). Therefore, it is very important to define, measure and improve quality of healthcare services. Quality, because of its subjective nature and intangible characteristics, is difficult to define. Definitions vary depending on whose perspective is taken and within which context it is considered. No single universally accepted definition exists. Quality, therefore, has been defined as 'value' (12); 'excellence' (13); 'conformance to specifications' (14); 'conformance to requirements' (15); 'fitness for use' (16); 'meeting and/or exceeding customers' expectations' (17), and 'consistently delighting the customer by providing products and services according to the latest functional specifications which meet and exceed the customer's explicit and implicit needs and satisfy producer/provider' (18).

Healthcare service quality is even more difficult to define and measure than in other sectors. Distinct healthcare industry characteristics such as intangibility, heterogeneity and simultaneity make it difficult to define and measure quality. Healthcare service is an intangible product and cannot physically be touched, felt, viewed, counted, or measured like manufactured goods. Producing tangible goods allows quantitative measures of quality, since they can be sampled and tested for quality throughout the production process and in later use. However, healthcare service quality depends on service process and customer and service provider interactions $(19,20)$. Some healthcare quality attributes such as timeliness, consistency, and accuracy are hard to measure beyond a subjective assessment by the customer.

It is often difficult to reproduce consistent healthcare services. Healthcare services can differ between producers, customers, places, and daily. This 'heterogeneity' can occur because different professionals (e.g. physicians, nurses, etc.) deliver the service to patients with varying needs. Quality standards are more difficult to establish in service operations. Healthcare professionals provide services differently because factors vary, such as experience, individual abilities, and personalities (21). Healthcare services are simultaneously produced and consumed and cannot be stored for later consumption. This makes quality control difficult because the customer cannot judge 'quality' prior to purchase and consumption (22). Unlike manufactured goods, it is less likely to have a final quality check. Therefore, healthcare outcomes cannot be guaranteed. Quality healthcare is a subjective, complex, and multidimensional concept. Donabedian defined healthcare quality as 'the application of medical science and technology in a manner that maximises its benefit to health without correspondingly increasing the risk' (23). He distinguishes three components of quality: 1) technical quality, 2) interpersonal quality, and 3) amenities. Technical quality relates to the effectiveness of care in producing achievable health gain. Interpersonal quality refers to the extent of accommodation of patient needs and preferences. Amenities include features such as comfort of physical surroundings and attributes of the organisation of service provision (24).

Øvretveit defines quality care as the 'Provision of care that exceeds patient expectations and achieves the highest possible clinical outcomes with the resources available' (25). $\mathrm{He}$ developed a system for improving the quality of healthcare based on three dimensions of quality: professional, client, and management quality. Professional quality is based on professionals' views of whether professionally assessed consumer needs have been met using correct techniques and procedures. Client quality is whether or not direct beneficiaries feel they get what they want from the services. Management quality is ensuring that services are delivered in a resource-efficient way.

According to Schuster et al. good healthcare quality means "providing patients with appropriate services in a technically competent manner, with good communication, shared decision making and cultural sensitivity" (26). For Lohr, quality is "the degree to which healthcare services for individuals and population increases the likelihood of desired healthcare outcomes and is consistent with the current professional knowledge" (27).

Mosadeghrad defined quality healthcare as "consistently delighting the patient by providing efficacious, effective and efficient healthcare services according to the latest clinical guidelines and standards, which meet the patients needs and satisfies providers" (18). He identified 182 attributes of quality healthcare and grouped them into five categories: environment, empathy, efficiency, effectiveness and efficacy. Quality healthcare includes characteristics such as availability, accessibility, affordability, acceptability, appropriateness, competency, timeliness, privacy, confidentiality, attentiveness, caring, responsiveness, accountability, accuracy, reliability, comprehensiveness, continuity, equity, amenities, and facilities (20).

Various healthcare stakeholders' perspectives, desires and priorities must be considered in any effort to define, measure, and improve quality of healthcare. While several empirical studies have been carried out to assess the quality of healthcare organizations $(28,29)$, few researches have been conducted to identify factors that affect quality of healthcare services. Very limited studies have addressed this issue in Iranian healthcare organizations (30). Most studies were limited to one or at the most two healthcare stakeholder perspectives. This study, therefore, aims to fill this research gap by empirically exploring healthcare providers', managers', payers', and policymakers' perspectives on factors affecting healthcare services quality in Iranian healthcare organizations.

\section{Materials and methods}

Purpose

The main purpose of this study was to identify factors that influence healthcare services quality in the Iranian context.

\section{Method}

Owing to healthcare complexity and multi-dimensionality, research exploring healthcare quality is methodologically difficult. There are many participants involved in healthcare delivery, each having their own interests and concerns. Hence, quality assessment cannot be carried out reliably by asking one stakeholder alone. Pluralistic evaluation (31) can overcome professionally dominated healthcare evaluation traditions by identifying and representing stakeholder 
group views, including the marginalised. The pluralistic approach does not rely on consensus, but evaluates multiple perspectives. Hence, each stakeholder group has their views and concerns represented in the evaluation (32). As a result, objective findings can be obtained.

This study represents an exploratory effort in understanding factors affecting healthcare services quality in the Iranian context. A qualitative approach is appropriate to answer the research question. A qualitative research typically produces detailed and in-depth information about a much smaller number of people and cases. This increases understanding of the cases and situations studied and enhances the validity of the data obtained (33). It is often inductive, with propositions emerging at the end of the study rather than being hypothesis driven. However, the qualitative research is labour-intensive, costly, time consuming, and demands the highest level of expertise to undertake the research and interpret the findings (34). It also suffers the limitations in generalising the results to a larger population.

Interviews provide a useful means to access in-depth information on the attitudes and behaviors of subjects towards different phenomena (35). Interviews encourage the participant to tell 'the story' in their own words. This is most beneficial for this research. It enables the researcher to uncover factors that can affect healthcare services quality. However, interviews are not problem-free. They can be time consuming, costly, and prone to subjectivity and bias on the part of the interviewer (36).

Stakeholders' perceptions about what factors affect healthcare service quality often reflect their individual experience rather than a general view. Interaction between participants in focus groups can help overcome this. A focus group is a group interview technique designed to promote interaction between members of a group to stimulate deeper discussion, reduce social and cultural constraints on participation, and reveal new facets of the discussion topic (37). Focus group discussion generates qualitative data from a group of people much more quickly and at less cost than would be the case if each individual were interviewed separately. Focus groups allow the researcher to interact directly with respondents. This provides opportunities for the clarification of responses, for follow up questions and for probing of responses (38). Focus group discussion helps to explore factors influencing healthcare services quality and explain the reasons for their occurrence.

Therefore, in-depth individual and focus group interviews were conducted in this research using a semi-structured format with key healthcare stakeholders in Isfahan, Iran. These included healthcare providers (doctors, nurses, and paramedics), managers, policy-makers, and payers.

\section{Settings and participants}

The study was carried out at eight hospitals, four MoHME hospitals (three teaching and one non-teaching), two SSO affiliated and two private hospitals to represent the three dominant hospital care systems in Iran. In-depth interviews were used for gathering doctors, managers, policy-makers, and payer's perspectives. This study also relied on focus groups with providers (except doctors) to explore their opinions on factors affecting healthcare quality. In each hospital two focus group discussions were conducted with nursing staff and paramedics (See Table 1).

\section{Data collection}

A semi-structured interview schedule was designed for the study. The interview schedule consisted of open-ended questions to allow respondents to answer from a variety of dimensions. Participants were asked to articulate factors that facilitate the delivery of quality healthcare services. The interviews were recorded digitally with the participants' permission to facilitate analysis. Notes were taken for those participants who were reluctant about voice recording.

\section{Data collection and analysis}

The digital files were transcribed by the author himself. Content analysis was used to detect and code factors affecting quality of healthcare services, organise them into logical and meaningful categories, make connections between and among categories, and explain the link between categories. NVivo version 7 (QSR International, Australia) was used for qualitative data analysis and retrieval.

\section{Evaluating the quality of research}

The researcher has not allowed personal values to influence the conduct of the research and findings derived from it. Member checks (respondent validation) were done in face-toface discussions with a subgroup of participants in order to verify and validate the findings. The researcher also utilised peer debriefing with five quality management experts. Peer reviewers debriefed with the researcher by presenting a summary of the gathered data, categories and themes that emerged, and the researcher's interpretations of the data. The peer debriefers provided the researcher an opportunity to clarify his interpretations about the nature of quality healthcare and to examine his biases.

\section{Results}

The views of participants on factors influencing the quality of healthcare were grouped into three main categories and 10 themes (Table 2). Factors related to both the provider and receiver of the healthcare service and the environment affect the quality of provided services.

Table 1. Number of interviews and the codes

\begin{tabular}{llc}
\hline Groups & Participants and codes & N \\
\hline Providers & $\begin{array}{l}\text { 64 Individual interviews with physicians (MD) } \\
16 \text { Focus group discussions with other } \\
\text { providers (PRG) }\end{array}$ & 64 \\
Managers & $\begin{array}{l}10 \text { Individual interviews with managers (MA) } \\
\text { Policy-makers }\end{array}$ & $\begin{array}{l}10 \text { Individual interviews with policy-makers } \\
(\text { PM) }\end{array}$ \\
Payers & 10 Individual interviews with payers (PA) & 10 \\
Total & & 10 \\
\hline
\end{tabular}


Table 2. Factors influencing the quality of healthcare

\begin{tabular}{ll}
\hline Category & Themes \\
\hline Patient related factors & Patient socio-demographic variables \\
& $\begin{array}{l}\text { Patient cooperation } \\
\text { Type of patient illness }\end{array}$ \\
& Provider socio-demographic variables \\
Provider related factors & Provider competency \\
& Provider motivation and satisfaction \\
& Healthcare system \\
Environmental factors & Resources and facilities \\
& Leadership and management \\
& Collaboration and partnership development \\
\hline
\end{tabular}

Patient socio-demographic variables

Socio-demographic factors influence the interaction between a provider and the patient and consequently the quality of services. For instance, a physician stated "I worked in a health centre in a village. They [The patients] did not understand me. They talked in a different language. They did not even obey my [medical] orders. For instance, I asked a patient with pharyngitis not to eat sausage and pickled cucumber. He agreed not to do so. However, in the afternoon, I saw him with a tin can of gherkin and some sausages" (MD2). Another participant said: "Sociocultural issues make it difficult to have a desired outcome. I had a patient, a mother of eight children who was sick, and pregnancy was dangerous for her. She had the chance to abort the child legally but her husband wanted the child" (MD38). Healthcare professionals must be aware of and understand the socio-demographic characteristics of their patients to provide high-quality services. A physician said: "I personally check patient place of birth first to know where s/he from is. Then, I ask my questions in a way that is understandable for the patient to encourage him or her to answer my questions" (MD36).

Some patients ask their doctors to prescribe medicines. They believe that they will not be healed unless they take medicines. Patient persistence to get a specific medicine influences physicians to do so to satisfy the patient: "For a simple cold for which the patient needs supportive care, s/he insists to get penicillin. If I do not prescribe it, s/he will go to see another physician" (MD20). Some doctors believe that it is even useless to explain the treatment process to a patient demanding medicine: "Explaining the disease and its treatment process to a patient demanding a medicine for about half an hour will not satisfy him/her more than if you just prescribe antibiotics, which takes about 2 minutes of your time" (MD20).

Lack of a robust referral system and a low medical tariff are the main reasons for a doctor's tendency to meet patient (irrational) requests. Patients have easy access to affordable medical services: "Medical services are easily available. You can see a medical specialist easily whenever you want" (MD23). Therefore, patients can easily switch from one provider to another one. On the other hand, the high cost of running a medical clinic forces physicians to see more patients. " $A$ physician has to pay for the rent, bills, tax, and secretary wages. The income from the first 18 patients goes to the expenses [breakeven-point]. Therefore, s/he has to see more patients". (PM2) "When medical tariff is low, a physician has to compensate it with quantity [seeing more patients]" (MD18).
Patients' financial status may affect the quality of healthcare services. Sometimes the patient cannot afford the costs associated with his or her treatment and decides to cancel the treatment. If the patient does not follow the doctor's orders due to financial problems, the treatment will not be effective. A physician said: "I prescribed a patient a [clinical laboratory] test and some medicines. She came back with the prescription two weeks later and said 'Doctor I am still ill!' She could not afford the medicine and the [clinical] test" (MD28).

Quality of patient care depends directly on the quality of patient education and responsibility. Patients' knowledge of their rights influences their expectations of quality services: "If people know about their rights [in hospitals], they would expect more from their care-givers and consequently the quality [of medical services] increases" (MD33). More educated patients have more realistic expectations of the healthcare providers. A physician commented, "I might unconsciously explain more to an educated patient. I assume that s/he would understand better" (MD37). Participants believe that patients who come to the private hospitals would expect more as they are paying more for the services.

The patient's attitude and behaviour also affects the attitudes of care-givers. If a patient behaves himself or herself, caregivers unintentionally provide better services: "If the patient is grumpy, the physician has no motivation for further examination. I had a very polite and eloquent patient today. One is interested in asking more questions" (MD20). Some participants asserted that patient recognition affects the quality of provided services. "If I see that a patient acknowledges my efforts, I will do my best. Otherwise, I just do my job. The patient's behaviour unintentionally affects my work" (MD7). "When a patient, or his or her relative, says 'thank you' to me, I feel motivated to do my job better" (PRG1).

\section{Patient cooperation}

Patient involvement and cooperation is needed and affects the quality of healthcare service. "If the personnel do their job well, but the patient does not follow medical orders, the objectives would not be achieved" (MD50). Clinical outcomes depend on the ability of patients to provide information and cooperate with clinicians. A physician said: "I explained to a patient that this medicine might cause bleeding. So, if [he had] any history of heart problems or internal bleeding [he should] let me know. $\mathrm{He}$ [The patient] said 'I do not have any problem'. Later, when his wife brought his medical records, I found out that he had a heart attack last year. I stopped the medicine immediately. I could not even sleep all night and was under stress [to make sure he was OK]" (MD52).

Some participants complained about the lack of patient cooperation in the treatment process: "Sometimes, the patient does not cooperate. For example, s/he needs a suppository, but does not use it" (PRG1). "I explained to a patient that she should not eat anything because she just came back from the operation room. Later, I saw her drinking water. She said: 'I was thirsty!" (PRG5). "The patient does not take the medications completely at home after being discharged from the hospital and returns within 5-6 days" (PRG11). "I have to prescribe fast-effect medicines. The patient does not take a long-term effect medicine completely. Whenever s/he feels better, she stops taking it" (MD30). 
Doctors considered patient trust a key factor in achieving the desired outcomes. Factors which help improve the physicianpatient relationship are providing more information about the disease and the process of treatment, good interpersonal relations, the physician's appearance, word of mouth, having good previous experiences with the doctor, and the doctor's demographic variables like age.

\section{Type of patient illness (severity of illness)}

The type of patient illness influences personnel job stress, which in turn affects overall quality of healthcare services: "When I came to this hospital [Cancer hospital], I was getting depressed. It took about 6 months to get used to it" (PRG15). "When I see that a beautiful young girl got a cancer and is going to die, I get upset" (MD57). "Mortality rate is high here. Since yesterday 5 patients died. This causes anxiety and stress among staff" (MD59). "Patients in our ward [ICU] are high risk. We always feel stressed" (PRG5). "We had a patient with hepatitis. There is a need for an isolation room which is not here" (PRG1).

\section{Provider socio-demographic variables}

The character and personality of healthcare provider affect the quality of healthcare services. "The physician's appearance and relations with a patient affects the quality of service" (MD52). Medical doctors develop good rapport with their patients using some personality characteristics such As respect, helpfulness, reliability, intelligence, and confidence: "Physician personality is important. Some physicians built a good relationship with patients. It helps patient to trust the doctor and cooperate in the treatment process" (MD46).

However, there should be a link between physicians' attitude and communication with patients and their received income. In a public hospital that the demand for medical services is very high, physicians are not motivated to improve their communication skills: "Some doctors particularly in public hospitals realized that their communication skills are not linked to their income level. Thus, they may not change their attitude and behavior" (MD7).

Providers' personal and family problems also influence their behaviour and the quality of services provided to patients. Some participants raised these kinds of issues by asserting that: "Being happy with the personal life affects the work of a physician" (MD37). "Family problems decrease the quality of services" (PRG5). "I have a child to take care of. Therefore, I have less time for study" (MD7). "I have a cancer patient at home who needs caring for. It engages my thoughts while I am working here" (PRG1).

\section{Provider competence (Knowledge and skills)}

The quality of healthcare services mainly depends on practitioners' knowledge and technical skills: "the most important factors influence the quality of my work are my knowledge, expertise, commitment, and examining the patient properly" (MD1). Healthcare professionals should improve their competencies (i.e. the attitudes, knowledge, and skills) to deliver high-quality services. "I have to be updated. My knowledge benefits patients. For example, Nifedipine is used to reduce blood pressure. According to the latest evidence, it causes CVA. Hence, resources like Internet, journals, and books should be available for me" (MD2). "Our caring should reach international caring standards. More in-service training should be provided for us" (PRG11).

Medical universities have a critical role in providing education and professional development opportunities for the healthcare workforce. Unfortunately, most healthcare professionals are not satisfied with the quality of education in the universities "There are some shortcomings in the medical education" (MD6). "The graduates are not practically competent" (MD3). "In the university we learn more theory. We have no practical experience" (MD22). Healthcare professionals demanded more relevant and practical education and training. "We are taught about some rare or uncommon diseases that we will forget later. For the common diseases there is just theoretical education" (MD37). "The way to communicate with patients is not taught" (MD3). "There is no formal education in medicine prescribing. I have to learn that by myself." (MD7) and "The theoretical perspective of nursing education is good. However, graduates are not practically competent" (PRG15).

Therefore, hospitals provide additional education and training to meet employees' educational needs. However, the effectiveness of the education provided is questionable: "The hospital provides some educational programmes. However we are so tired that we end up sleeping in the class". (MD15) and "Working too much reduces the motivation for study. I have to work 216 hours a month" (MD46).

\section{Provider motivation and satisfaction}

Providers' job satisfaction is very important in delivering highquality services to patients. Healthcare providers identified nine organisational factors they believed influence their motivation and consequently job satisfaction. These were pay, working environment, managerial leadership, organisational policies, co-workers, recognition, job security, job identity, and chances for promotion.

Participants mostly expressed their satisfaction with the job they were doing: "I like my job. I feel satisfied when I see that I saved people life. I have a good feeling when I see my diagnosis and treatment were right and effective" (MD2). However, they were dissatisfied with the payment particularly in public hospitals. "I have to work in other hospitals as well to be able to afford living expenses. Too much work decreases my motivation" (MD2). Throughout every focus group discussion with healthcare employees, the common reason for their dissatisfaction was insufficient and unfair pay and benefits. "An employee with a diploma working in a university hospital earns 3 million RLS per month, while his counterpart in a social security hospital earns 6 million RLS" (PRG2). "My colleague in hospital X gets over 1 million per-case while mine is 300,000 RLS. I am covering 28 patients while he does 1012 patients" (PRG5). There are inconsistencies regarding pay rates among healthcare settings.

More and more qualified employees are leaving private hospitals as soon as they find a secure and well-paid job. For instance, Isfahan University of Medical Sciences advertised for the recruiting of clinical staff in 2008. Many of the employees, especially nurses in private hospitals left their jobs after the attainment of a position in a public hospital. A head nurse said, "Four of my best staff left the hospital. They are now working in a public hospital". A nurse who left a private hospital to work in a public one explained her reason as: "I worked two 
weeks in the CCU ward at hospital ' $G$ ' [a private hospital]. I left it because of too much work and low wages. My colleagues were excellent. The working environment was good. I felt it more convenient to work there than here [public hospital]".

High employee turnover causes many problems for operational managers. Most of the newly employed personnel do not have work experience. Therefore, the education supervisor or department head have to train them. A head nurse said, "I asked a [recently employed] nurse to send the patient to the Operation Theatre. Later, the head nurse of the Operation Theatre phoned me and said, "Why did you send the patient in this way? She [the new nurse] had sent the patient without preparing and accompanying her!" (PRG3). She further added: "They are not experienced enough. When I ask one of them to measure the patient's blood pressure, I have to ask another colleague to do it again".

Some employees of public hospitals work in a private hospital mostly in the afternoon and night shifts to cope with their living expenses. In such cases, the quality of their services will be decreased due to too much work. This in turn affects patient satisfaction. It also affects other staff's motivation and satisfaction: "We have a colleague here who works in Hospital ' $X$ ' as well. He earns about 1 million RLS over there. Here is a place for him to rest and when I ask him to do some work, he says, "How much do you think I earn here to do all these jobs" (PRG13). "This is his second job. He does not contribute too much and we have to cover most of the job ourselves" (PRG4). Furthermore, the pay gaps among professionals in a healthcare setting are very wide. A head nurse said, "The nurses in the Psychiatric Emergency Ward receive a 100\% hardship allowance, while we get 70\%. ICU nurses even get $10 \%$ more than us" (PRG1); "A newly employed B.Sc. nurse receives more than me [a nurse's aide with 26 years of working experience]" (PRG1); "My [General Practitioner] per-case is one-twentieth of a medical specialist" (MD1); "The tariff of a dentist is 70,000 RLS, but for a GP [General Practitioner], it is about 20,000 $R L S^{\prime \prime}$ (MD46).

It was very important for employees to see that their contribution is recognised and valued by managers, even if only symbolically. One participant said, "If I do thousands of good things, they [managers] do not recognise my efforts, but if I make a small mistake, I will be punished for it. I saved the life of a patient with pulmonary oedema, while the physician was not in the ward. Nobody appreciated it. The supervisor scrutinised me later, when she checked the patient's medical record and found that I forgot to write up a teaspoon of medication" (PRG3). "There is no recognition for a person who performs the job well" (MD46).

The opportunity for professional development does not always seem to be encouraged by managers as explained by several respondents. "I have attended about 1000 hours in-service training classes, but there is no promotion for me" (PRG1); "I have been working here for about 26 years. There is no promotion here for employees. If I had worked as a simple worker, I would now be at least a foreman" (PRG1). Some participants complained about the criteria for promotion: "The quality of my medical service is not important for my career promotion. The criterion is how many books and articles I have written" (MD24); "For promotion from GP to medical consultant, I have to pass an exam which is theory-based. My work experience does not count" (MD52).

Participants also stated that their motivation was influenced by the job security offered by hospitals: "Personnel have no job security here." (PRG4); "I cannot talk about the hospital problems. If I talk about them, managers would get mad at me" (PRG3); "There is no job security here" (PRG5, 8, 13, 20 , and 14).

The working environment affects employee satisfaction. "The working environment is important. Factors like an air conditioning system and light affect [the quality of] my work" (MD2). Participants expressed a need for a quiet and supportive working area. "The fan makes a terrible noise. It bothers me" (PRG6). "Working in the basement is tiring. When the work place is dark and closed, it causes me to feel upset. One may start the day happily, but this physical environment causes it to end it up sad" (PRG2).

Quality of leadership and management affects employees' motivation and satisfaction. A participant provided an example by putting a glass on the table and putting his hand over it and saying: "Imagine this glass is the patient, and this hand is me. If the manager puts me under pressure, I transfer the pressure to the patient" (PRG1). He further explained, "Nursing is more practical. I cannot do my job well in a stressful environment". A participant explained how a manager could reduce an employee's job stress: "A supportive manager helps a new employee to adapt to the working environment and reduces his/her [job] stress by providing necessary training and resources" (PRG1).

Some employees, especially first-line managers demand top management to give them more authority with regard to their daily activities: "Managers should empower head nurses to resolve ward problems by themselves" (PRG1). "Invoices should be signed and confirmed first by the deputy CEO [Chief Executive Officer] and then by the internal manager before being forwarded to the finance department for payment. It takes 10-15 days for a supplier to receive the payment. A finance manager does not have any power in this hospital" (PRG4).

\section{Healthcare system}

There is no referral system from the primary healthcare level to the secondary and tertiary levels in Iranian healthcare system. Therefore, there is a tendency, in patient choice from a GP to a medical consultant: "Lack of a referral system resulted in a shift of patient choice from general practice to sub-speciality practice. Most patients prefer to be seen by a medical specialist. Nowadays, a GP has fewer patients than a medical consultant" (MD3). Low medical tariff makes it easier for patients to see a medical specialist: "The disparity between the service fee of a GP and a [medical] consultant is not too much. Therefore, patients prefer to be seen by a medical specialist" (MD19).

Medical insurance companies make it even more affordable for patients to see a medical specialist. "95\% of my patients are insured and $90 \%$ of them at least visited one of my colleagues before coming to see me in the week" (MD24). "Insurance companies pay the medical expenses even if a patient visits three different physicians in just one day. That's why some patients visit a physician in the morning, then see another one in the afternoon and sometimes even the third one at night" (MD18). "The patient thinks, 'it costs me 7000 RLS, let's see what another physician says'. If s/he has to pay 40,000 RLS, s/he would say 
'let's get a result from this doctor's prescription, if I did not get better, I will see another one"' (MD60).

Furthermore, the fee for service of a doctor visit is the same for simple or more complicated cases. It leads to competition between the GP and the specialist, with the latter being perceived as holding the upper hand. Hence, there is no motivation for medical consultants to convince patients to be seen by a GP first, "I [medical specialist] can see either a patient with a simple bellyache or a complicated case with several liver diseases. The fee for both services is the same. It would be better for me to see the former as it takes less time and I can see more patients [and have more income]" (MD3). Moreover, lack of patient trust in medical doctors and lack of familiarity with medical practices increases uncertainty and leads to repeated medical visits. "A physician should convince the patient that they do care about the patient and there is no need to be worried about their illness. The situation is under control even if it takes a week to get better. If the physician does not decrease a patient's fear and just relies on examination and prescription, the patient will go to see another doctor" (MD42). As a result, the demand for specialised healthcare is increasing which is beyond the resources of healthcare organisations or even payers. Purchasers of healthcare services are concerned that the cost has exceeded their capacity and willingness to finance it: "Our resources are limited but [patient] expectations are unlimited" (PM5). "The demand for healthcare services does not match the resources of insurance companies" (PA1). "Social security hospitals are overloaded. Increased number of patients decreases the quality of services. Facilities and equipment are getting old. However, we cannot afford to renew them" (PA3). Hospital personnel particularly clinical staff who took part in the study complained that they were overworked and that there were staff shortages. "We have too much work to do. When I have to work 18 hours a day continuously, the quality of my work will decrease" (PRG8). "The public [healthcare] system suffers from staff shortage. I worked in a public hospital with average daily 200 patients in the outpatient department who had to be visited by 1 PM. I had to spend less time on each patient to be able to see all of them" (MD10). "The increasing number of patients demanding medical services does not allow us to work on quality [of medical services]. We are not dependent on patients. They are dependent to us" (P37).

Providers have to limit their flexibility and adaptability to the patients' individual needs due to staff shortages and time constraints: "I was working somewhere and had to see 60 patients from morning to noon. Thus, I had to spend 2 minutes on each patient instead of 20 minutes" (MD59). "For complicated cases I need at least 40-45 minutes to get a medical history and examine the patient thoroughly. During this time, my secretary calls me several times saying that we have a lot of patients waiting, and to please hurry up" (MD24).

The increased demand for medical services may force physicians to transfer patients to paramedical departments instead of having them properly examined to achieve an accurate diagnosis. "The time for visiting a patient is limited. Therefore, I cannot examine a patient properly and ask questions as these take time. I have to prescribe radiography. Then, by reading the report in a minute, I prescribe the medicine" (MD45). Some paramedics confirmed unnecessary referrals of patient to paramedical departments, "Ninety percent of the results of laboratory tests for some physicians in the $A \& E$ department are normal" (PRG10). "Sometimes 80 percent of the results of radiography films are normal" (PRG10).

Unnecessary patient referral to paramedical departments increases employees' work burden: "We have between 300-400 patients per day. Thus, we have to spend about 1 minute for each patient [to get the radiography film]. We have no time to explain the procedure to the patient" (PRG8). This in turn increases staff job stress, resource utilisation and probability of errors. "The patient number is a stressor. Sometimes 10 patients are waiting for the service [Radiology]. Thus, we have to speed up" (PRG10); "When there is much to do, employees get tired and the errors increases" (PRG11).

Participants, mostly policy-makers, managers, and doctors believed that the tariff of healthcare services do not match with the costs of providing the services. One interviewer asserted "An ICU bed costs the hospital 1.6 million RLS per night to provide services to a patient, while the tariff is 500,000 RLS. It means that if we keep the bed empty and do not admit a patient, the loss would be a third. The tariff should be realistic" (PM2). He further argued: "The government wants to provide affordable healthcare services. Therefore, providers have to cut costs. Consequently employee and customer are not satisfied". Participants hoped that making the medical tariff realistic decreases the demand for the services: "If patients have to pay the real cost of medical services, their unnecessary visits would be decreased. At least they would not visit a medical consultant for simple cases as they have to pay much more" (MD7). Lack of competition especially in public sector was also considered as a reason for ignoring quality in healthcare systems. "Quality is not a priority. There is lack of competition among healthcare providers. Government funds healthcare services. Thus, we may not think about quality of our services" (MD18). Some even suggested that the direct monetary link between the doctor and the patient has to be removed.

However, in Iran's centralised and bureaucratic public sector, all strategic decisions are taken by the managers up in the hierarchy. "The public sector is highly centralised and bureaucratic. Policy-makers are not involved in healthcare delivery. Therefore, their decisions are not realistic. Their approved budget is not enough for running these [healthcare] organisations" (MA9). As a result, the allocated budget does not match with the costs of providing healthcare services. "Management organisation says that a hospital should have 1.73 personnel per each bed, but we [in Ministry of Health] say at a minimum we need 3.5 per bed" (PM1). "The health ministry says that in the best situations, it is impossible to provide healthcare services lower than 10 US dollars per capita. However, the government budget for healthcare per-capita is 3 US dollars" (PM5).

A number of participants believed that medical and healthcare service fees should be changed. "We lack funds for quality improvement unless the medical tariff is determined realistically. I have to spend the entire hospital budget on purchasing supplies" (MA2). "If I want to increase hospital income, I have to improve employees' motivation. I cannot afford the costs. I cannot spend enough on employees' development and training" (MA9).

Resources and facilities

Availability of resources affects the quality of healthcare 
services. "There is just one [medical] manometer in the ward. It affects the quality of the overall work" (MD25). "There is the need for an information system. We need to have a record of patient history. It is very useful, especially for patients with blood pressure or diabetes. Thus, we will be able to see the effect of the treatment on patient by reviewing his or her record" (MD35). High-quality outputs (services) require high-quality inputs. Working with low quality material decreases employees' productivity. "[Medical] equipment is old. Therefore, it takes more time to do our job. For example, it takes about 40 minutes to get an ECG [Electrocardiography] with the equipment we are using" (PRG5). "It takes more time to work with old equipment. The results may not also be reliable. For example, getting a patient's VS [Vital Signs] takes about 30 minutes. It can be done in less than 1 minute by using modern equipment" (PRG5).

The resource shortage also increases employees' job stress, which consequently affects the quality of their work: "The DC Shock machine in the operation room does not work. When I am at home, I stress over what would happen if a patient does need it" (PRG1). "One of our pieces of equipment does not work well. The reserve is out of order. I sleep every night with stress" (PRG2); "We had a patient with hepatitis. There is a need for an isolation room which is not here" (PRG1).

Managers and policy-makers recognised financial resources as the most important factor affecting the quality of healthcare: "Now, money is the most important factor. While we cannot pay employees salaries, how can we talk about quality?" (PM1); "A good job cannot be done on an empty pocket... Financial resources are essential in organisations. Organisations' differences in financial resources affect their quality of service" (MA6).

\section{Leadership and management}

Effective management was mentioned as an important enabler of quality from the perspective of providers, managers, policymakers and payers. "Everything in the hospital is affected by the management. If people have good ideas for quality improvement, but there is no good management, those ideas would be useless". (PRG8). Some participants complained about the lack of professional managers in healthcare organisations; "Management is not professional here [hospital]. They do not have experience and knowledge in management. They just try to resolve problems in short terms" (PRG2). There are no objective criteria for selecting and appointing managers in healthcare organisations: "There are no criteria for recruiting or dismissing managers" (MA5). "Managers' selection and appointment is not based on objective criteria. It is based on personal connections" (PM4).

The analysis of qualitative data indicated that the lack of management stability was considered a major obstacle facing the managers trying to extend their knowledge and experience. "There is no job security for managers. When a [top] manager changes, operational managers change as well" (PM4).

Managers in public hospitals do not have the ultimate power for decision-making. National policies are extremely prescriptive and do not allow sufficient flexibility to adapt to local circumstances. "The Ministry of Health develops universal policies for the entire country without considering local factors. A manager does not have enough authority to change it [adapt it]. The Ministry of Health should define the indicators and ask managers to achieve them. The ways to achieve indicators should not be dictated" (AC1). "A framework has been defined for managing the organisation [It is not flexible] and we have to manage within this defined framework with limited resources" (MA10). "A manager cannot change the structure. If you cannot change the structure, you cannot execute a decision easily" (MA9).

Healthcare managers demand more power in identifying and recruiting the most appropriate personnel to provide quality service. "If managers are empowered enough to recruit competent employees, most problems would be resolved" (MA3). Furthermore, managers cannot control physicians the same way as other employees. "As a manager I do not have the power to control physicians. The medical school decides who should practice in the hospital. For instance, it was decided that a paediatrician should work at the hospital on Sundays. I have 100 patients waiting for service, but s/he [doctor] says 'I have my own students as well [training] and cannot see more than 30 patients" (MA9).

\section{Collaboration and partnership development}

For practitioners having good support services is important: "I need to be assured that the clinical laboratory works well [the test results are reliable], and that the nurse administers medicines on time or does not administer a wrong medicine" (MD14). "I asked the CSSD [Central Supply Sterilization Department] to give me a sterile dressing set. She said that she does not have it. They should be more responsible. They should have reserves for the sets there" (MD7).

Medical doctors expect their colleagues or co-workers to be more responsible and be empowered enough to perform the job well. "A nurse spends more time with patients than a doctor. $S /$ he should tell the doctor the patient's problem to help him/her with a proper decision" (MD38). "I expect a nurse to perform the job well. Instead of just picking up the phone and telling me that the patient has pain, s/he [the nurse] should evaluate the patient first, takes the patient's ECG and vital signs and tells the doctor patient condition with more details" (MD59).

Healthcare professionals highlighted the importance of cooperation and teamwork among healthcare providers as an important component of high-quality healthcare services. A laboratory supervisor said, "Sometimes, doctors do not give the necessary information to patients. For example, for some hormone tests, the patient must not eat a specific food. It affects the quality of the results" (PRG8). Another participant said: "Some physicians do not give a copy of patient's medical records to the patient. If s/he has to see another physician in an emergency situation, the doctor does not know anything about the patient's medical history" (MD10).

Practitioners' ability to effectively communicate and collaborate with other health professionals or institutions was also considered essential to the delivery of high-quality healthcare services. "The hospital does not have a CT-Scan. A patient's relative has to get an appointment from another hospital and then take the patient there for the CT-Scan. S/ he has to go there once more to get the result. All these can be sorted out easily through collaboration between two hospitals. A nurse can call the other hospital to get an appointment for the patient, then send the patient for a CT-Scan and later receive the results" (MD4). 
The lack of collaboration between healthcare organisations and other organisations influence service quality. "The price of Streptokinase [a thrombolythic drug] went up suddenly from 120,000 to 9,400,000 RLS per vial a couple of weeks ago. Normally, the hospital sends the bills by the end of every month to the [insurance] company. It takes time to get the money back [due to bureaucracy]. It is difficult for the hospital to manage the new price. Therefore, patients are asked to buy the medicine themselves from the pharmacy and then claim the money from the insurance company. It causes inconvenience for patients. There is a need for collaboration between the hospital and insurance company to solve these kinds of problems" (PA3).

\section{Discussion}

Quality in healthcare is a production of cooperation between the patient and the healthcare provider in a supportive environment. Healthcare service quality depends on personal factors of the healthcare service provider and the patient and factors pertaining to the healthcare organisation and broader environment. Differences in internal and external factors such as availability of resources and collaboration and cooperation among providers affect the quality of care and patient outcomes. A number of theoretical relationships can be inductively inferred from the preceding analysis. These relationships are depicted in Figure 1.

This model illustrates a variety of individual, organisational, and environmental factors that influence a caregiver's job satisfaction and consequently commitment in providing highquality services. Individual factors include age, personality, education, abilities, and experience. Organisational factors include management style, working conditions, and relationships with co-workers. Environmental factors consist of economic and social influences. Furthermore, customer related factors such as socio-demographic variables, attitude, and cooperation influence the quality of care provided. The provider's subjective attributes, including the priority they give to care, would have a moderating influence on the delivery of care.

This study showed that hospital employees burdened with heavy workloads, poor compensation packages, low quality of work life, and poor leadership. All of these factors have impeded the delivery of quality patient services particularly in the public health sector. These findings are consistent with previous studies in Iran (39-44). In this study, clear relationships between employee satisfaction, quality of care, and patient satisfaction was found. These findings support earlier researches $(45,46)$. Good human resource management drives employee satisfaction and loyalty $(47,48)$. Effective human resource management can also have a significant effect on customer satisfaction. Satisfied and committed employees deliver better care, which results in better outcomes and higher patient satisfaction (49-51).

The findings suggest that healthcare quality can be improved by supportive leadership, proper planning, education and training, and effective management of resources, employees, and processes. If policy-makers and managers intend to improve healthcare services quality, they should apply techniques and tools to operationalise these quality management constructs. However, there are some obstacles that prevent the successful introduction of quality management models. Some of these organisational morbidities are explained below.

Centralization, bureaucracy, and severe dependency on government with a strong hierarchical structure are important barriers to effective quality management in the Iranian healthcare system. Almost all decisions regarding the structures, general goals, policies, and even resource allocation are made at the central level by the MoHME. Managers in public healthcare organisations do not have autonomy to make and implement strategic decisions. An effective quality management system requires more autonomy for operational managers in the decision-making processes. The MoHME determines health policies, delivers, and evaluates healthcare services. While the ministry of health participates in developing standards and policies, an accreditation council comprising representatives from government regulatory agencies, professional organisations, practitioners, and the public should be created to govern the accreditation programme. Quality management principles should be incorporated into healthcare evaluation

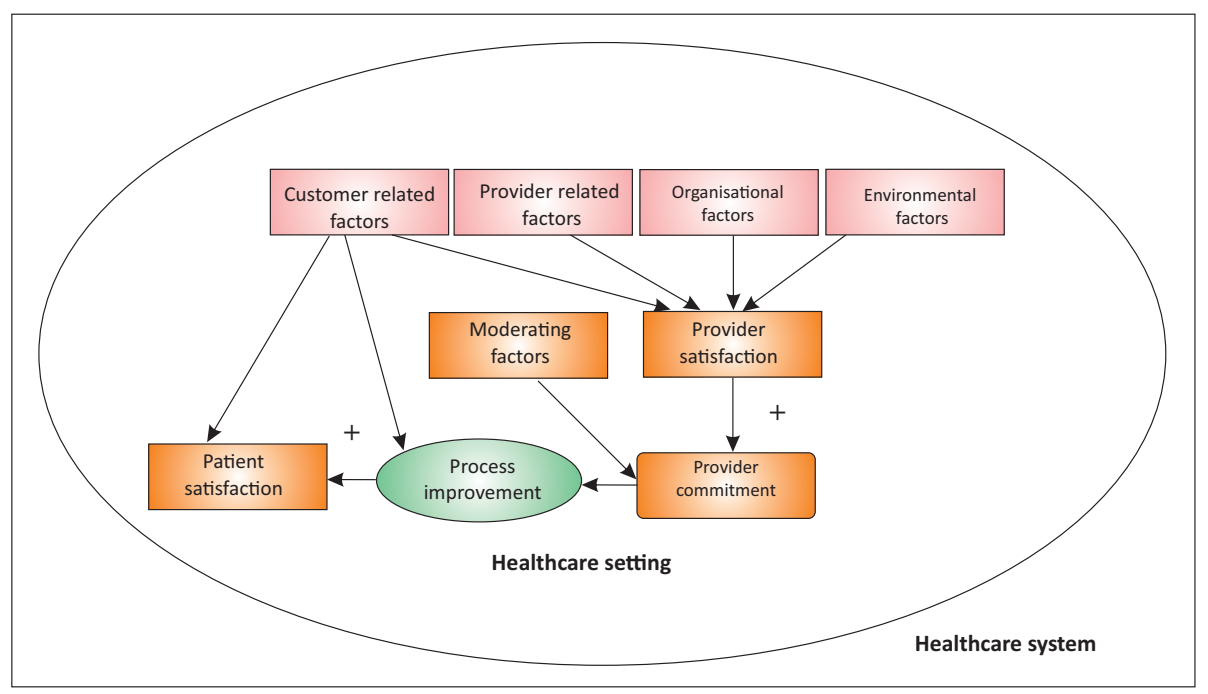

Figure 1. A proposed model of factors affecting the quality of healthcare services 
and accreditation standards.

Several ministries, organisations, and institutions are involved in the provision of healthcare services in Iran, which make the healthcare system less efficient. They pay differently to their employees. It resulted in a feeling of inequity, de-motivation and dissatisfaction among employees. The quality and tariff of services are also different in these healthcare organisations, leading to patient dissatisfaction. Nationalisation of healthcare services decreases the feeling of inequity among healthcare providers and clients. Many Iranians cannot afford the costs of healthcare services on their own. There are many public and private medical insurance programmes in Iran. A national (Universal) programme of comprehensive health insurance helps to decrease the inequity in access to services for patients. It is very difficult to sustain the benefits of a quality management system in Iranian healthcare organisations while they are suffering from these organisational diseases. Managers and policy-makers must invest in the following five capitals (see Figure 2) to overcome the above-mentioned obstacles and facilitate the implementation of quality management (52).

Physical capital refers to any non-human asset used in the production of products and services. Quality is not free. High-quality resources are needed to provide high-quality services. Healthcare organisations should provide their staff with the resources and support they need to deliver highquality services (52). In 2010, Iran spent 5.3\% of its Gross Domestic Product (GDP) or 302 US dollars per capita on health versus 3,495 US dollars in the UK, and 8,233 US dollars in the USA (4). A much higher percentage of the national GDP should be allocated to the healthcare system to improve healthcare services quality. The organisational structure in Iranian healthcare organisations should be changed to support quality improvement activities. The new quality structure should be supported by adequate staff, facilities, and resources. A clinical governance system should be established for defining clinical standards and monitoring performance against standards (53). Using a quality-oriented information system helps in studying the processes and identifying and then prioritising quality problems.

Human capital refers to the skills, experience, and knowledge gained by an employee to perform the job well. The quantity and quality of healthcare providers affect the quality of services. High-quality providers are critical to producing high-quality outcomes. Healthcare managers should have distinctive approaches for the attraction and the retention of qualified

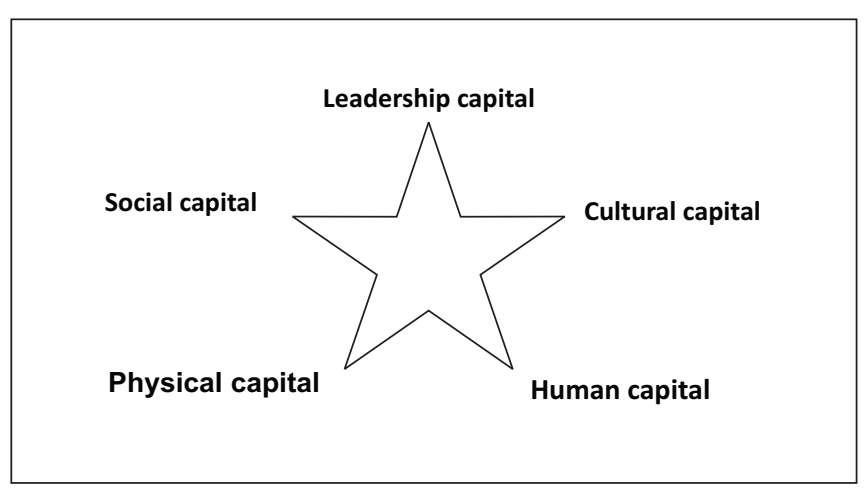

Figure 2. Star Capital employees that are able to deliver the highest-quality care. The current recruitment policies and practices in Iran should be reviewed to support managers in identifying and recruiting the most appropriate personnel to provide a quality service. This might involve operational managers and supervisors in staff selection and the use of performance-related criteria and psychometric tests for selecting staff. Continuing professional development is the most important investments in human capital. Peer review and professional revalidation also help to develop employees' capabilities. Employees' training takes time, expertise, and money. Therefore, universities should play a more active role in the effective training of human resources for healthcare organisations. Medical universities should offer quality-related courses in their academic programmes for medical and paramedical students. In addition, a continuous organisational learning team should be organised within the healthcare organisations to meet further employees' educational needs. This study emphasised the need to properly reward and recognise employees. Employees perform better when they feel recognised and appreciated (54). Employees' payments should be linked directly to the quality of their services, their performance and customer satisfaction. The fee-for-service payment method can discourage cooperation and collaboration across the delivery system in providing of effective and efficient healthcare services as it encourages providers to provide more services for the patients to maximise their own economic interests.

Social capital is about one's responsibility and accountability to society and human beings. It consists of the norms, obligations and trust embedded in social relations, which enable participants to act together more effectively and to pursue shared objectives (55). Accountability, coupled with transparency of information, help improve social capital. Professionals must be accountable to those they serve for the quality of care delivered. Delivering high-quality healthcare services is a corporate social responsibility of an organisation. Although improving productivity has been emphasised in the Iranian national development plan, there is no criteria for measuring achievement. Therefore, managers are not responsible enough towards increasing the productivity of healthcare organisations through the improvement of the quality of services. Regulatory bodies can support accountability through their core functions. This includes maintaining a register of professionals, setting standards for education and training, requiring continuing professional development, and providing guidance on standards and ethics. Education has a very powerful and positive effect on social capital.

Successful quality management implementation requires a significant change in mindsets, attitudes, and beliefs of individuals with regard to quality. Teamwork and collaboration should be fostered. Good communication, cooperation, and collaboration among healthcare providers support providing effective and efficient healthcare services, and promote shared responsibility for patient care. In Iranian healthcare, decisionmaking is centralized, the workforce is not empowered and there is a lack of trust amongst managers and employees. Mistakes bring blame seeking and dismissal and teamwork is thought to be unnecessary. Changing established behaviour and practices of an organisation is not easy (56). Education 
of the next generation in schools and universities on participation and teamwork concepts and skills, continuous improvement, and customer focus by the national TV or radio, ISIRI, etc. could be helpful. The increasing complexity of healthcare services, treatment options and care pathways requires a more knowledgeable and participative customer to achieve the most satisfactory outcomes. More active informed customer involvement reduces inappropriate use of healthcare services and errors and improves the quality of services through constructive criticism. However, customers lack knowledge about their rights in Iranian healthcare organisations $(57,58)$. The media and education system must play an active role in increasing public knowledge about healthcare services. Customer advocate institutions like the National Council for Quality Healthcare and the patients association should be established at the national level to make sure healthcare organisations are accountable enough in providing high-quality services. Healthcare organisations should also establish a patient relations department to provide patient advice and liaison service.

The success or failure of quality management is first of all in the hands of leaders (59). Leadership capital is the leader's ability to direct an organisation forward in a positive direction. It is important that managers develop their leadership skills and demonstrate their commitment to quality by establishing a shared vision and setting a clear direction for the organisation. Managers should transform their organisation's value system and ultimately the organisational culture, policies, and structure in order to meet the needs of their employees and customers. Iranian healthcare managers have been blamed for being short term oriented, conservative, non-participative, and non-scientific $(60,61)$.

Medical doctors without management expertise have occupied most of the managerial key positions in Iranian healthcare organisations. They rely more on practical experience as a vehicle for learning about management (60). Decision-making tends to be based on intuition rather than use of reliable information. As healthcare organisations are growing in number and complexity, there is an ever-growing need for professional management and governance that is accountable for continuously improving corporate (clinical, operational, and financial) performance. The introduction of professional management into the healthcare system increases managerial control of services and promote organisational productivity. Iranian healthcare organisations can be managed better by having well-trained managers supporting and leading the teams that manage the processes to deliver the best possible care for patients. Findings of this study confirm that managerial knowledge and skills are key success factors for the effective management of an organisation. Leaders' personality traits are also crucial to leadership effectiveness in organisations. These include personal motivation, enthusiasm, intelligence, conscientiousness, self-confidence, skill in dealing with people, and capacity to motivate others $(62,63)$. A programme should be developed to select, train, and develop professional managers for healthcare organisations. Training opportunities must be offered to help managers develop their management and leadership skills. Quality management methods should be also integrated into the management education curriculum. The MoHME should invest considerably in leadership development programmes for clinicians and managers.

\section{Limitations and implications for further research}

Respondents were healthcare organisation stakeholders in Iran and the results of the study cannot be generalised to other countries or healthcare systems. Hence, future studies may want to explore and identify factors that affect quality of healthcare services in other countries. The model presented in this paper needs to be confirmed empirically.

\section{Conclusion}

The pluralistic evaluation in this study revealed a comprehensive picture of factors affecting quality and the reasons for their occurrence in a way that would not have been possible had a singular evaluation approach been used. As the demand for healthcare services is increasing, most healthcare organisations find themselves overwhelmed with large volumes of patients. With such robust market, many providers cannot justify the cost of trying to improve the system. The majority of healthcare providers involved in this study stressed that quality of healthcare services is severely limited by lack of resources. In such a context, patient concerns could not be taken into account. In addition, public healthcare organisations deal with frequent management turnover. Important changes are required in a number of aspects of healthcare system in Iran if healthcare organisations are to provide high-quality services.

Ethical issues

Ethical codes in this study involved (i) respect for human dignity, (ii) respect for privacy and confidentiality, and (iii) respect for autonomy.

Competing interests

The author declares that he has no competing interests.

Author's contribution

AMM is the single author of the manuscript.

\section{References}

1. Mosadeghrad AM. Principles of healthcare management. Tehran: Dibagran Tehran; 2003.

2. World Health Organization (WHO). Islamic Republic of Iran: The role of contractual arrangements in improving health sector performance. World Health Organisation, regional office for the eastern Mediterranean. 2010. [cited 2010 February 10]. Available from: http://gis.emro.who.int/HealthSystemObservatory/PDF/ Contracting/Iran.pdf

3. Mehrdad R. Health System in Iran. Japan Medical Association Journal 2009; 52: 69-73.

4. World Health Organization (WHO). World Health Statistics 2013. Geneva: WHO; 2013.

5. Aghamollaei T, Zare $\mathrm{SH}$, Bodat A. Patients perception and expectation about healthcare services in Bandarabas healthcare centres. Journal of Hormozgan University of Medical Sciences 2007; 11: 173-8.

6. Mohammadi A, Shoghli AR. A survey on quality of primary health care in Zanjan district health centres. Journal of Zanjan University of Medical Science 2008; 16: 89-100.

7. Simbar M, Ahmadi M, Ahmadi G, Alavi-Majd HR. Quality assessment of family planning services in urban health centres of Shahid Beheshti Medical Science University. Int J Health Care 
Qual Assur 2006; 19: 430-42. doi: 10.1108/09526860610680076

8. Tabibi J, Maleki MR, Mojdehkar R. Measuring hospital performance by using Bldridge model. Journal of Iranian Medical Association 2009; 27: 23-30.

9. Lagrosen $\mathrm{Y}$, Lagrosen $\mathrm{S}$. The effects of quality management -a survey of Swedish quality professionals. International Journal of Operations \& Production Management 2005; 25: 940-52. doi: 10.1108/01443570510619464

10. Rahman S. A comparative study of TQM practice and organisational performance with and without ISO 9000 certification. International Journal of Quality \& Reliability Management 2001; 18: 35-49. doi: 10.1108/02656710110364486

11. Alexander JA, Weiner BJ, Griffith J. Quality improvement and hospital financial performance. Journal of Organisational Behaviour 2006; 27: 1003-29. doi: 10.1002/job.401

12. Feigenbaum AV. Quality control: Principles, practice, and administration. New York: McGraw-Hill; 1951.

13. Peters T, Waterman R. In search of excellence: lessons from America's best run companies. New York: Harper and Rowe; 1982.

14. Gilmore HL. Product conformance. Quality Progress 1974; 7: 16-9.

15. Crosby P. Quality is free. New York: McGraw-Hill; 1992.

16. Juran J. Quality control handbook. $4^{\text {th }}$ ed. New York: McGrawHill; 1988.

17. Parasuraman A, Zeithaml VA, Berry LL. A conceptual model of service quality and its implications for future research. Journal of Marketing 1985; 49: 41-50. doi: 10.2307/1251430

18. Mosadeghrad AM. Healthcare service quality: Towards a broad definition. Int J Health Care Qual Assur 2013; 26: 203-19. doi: 10.1108/09526861311311409

19. McLaughlin CP, Kaluzny AD. Continuous quality improvement in health care. $3^{\text {rd }}$ Ed. Sudbury, MA: Jones \& Bartlett Publishers; 2006.

20. Mosadeghrad AM. A conceptual framework for quality of care. Mat SocMed 2012;24:251-61. doi: 10.5455/msm.2012.24.251-261

21. Mosadeghrad AM. Towards a theory of quality management: an integration of strategic management, quality management and project management. International Journal of Modelling in Operations Management 2012; 2: 89-118. doi: 10.1504/ ijmom.2012.043962

22. Ladhari R. A review of twenty years of SERVQUAL research. International Journal of Quality and Service Sciences 2009; 1: 172-98. doi: 10.1108/17566690910971445

23. Donabedian A. The definition of quality and approaches to its assessment. Ann Arbor: Michigan Health Administration Press; 1980.

24. Donabedian $\mathrm{A}$. The quality of care: How can it be assessed? JAMA 1988; 260: 1743-8. doi: 10.1001/jama.260.12.1743

25. Øvretveit J. Does improving quality save money? A review of evidence of which improvements to quality reduce costs to health service providers. London: The Health Foundation; 2009.

26. Schuster MA, McGlynn EA, Brook RH. How good is the quality of health care in the United States? Milbank Q 1988; 76: 517-64. doi: 10.1111/1468-0009.00105

27. Lohr K. Medicare: A Strategy for Quality Assurance, Vol. I. Washington, DC: National Academy Press; 1991.

28. Jun M, Peterson RT, Zsidisin GA. The identification and measurement of quality dimensions in health care: Focus group interview results. Health Care Manage Rev 1998; 23: 81-96.

29. Padma P Rajendran C, Sai LP. A conceptual framework of service quality in healthcare: Perspectives of Indian patients and their attendants. Benchmarking: An International Journal 2009; 16: 157-91. doi: 10.1108/14635770910948213

30. Shahidzadeh-Mahani A, Omidvari S, Baradaran HR, Azin SA. Factors affecting quality of care in family planning clinics: A study from Iran. Int J Qual Health Care 2008; 20: 284-90. doi: 10.1093/intqhc/mzn016

31. Smith G, Cantley C. Assessing health care: A study in organisational evaluation. Milton Keynes: Open University Press; 1985.

32. Hall JE. Pluralistic evaluation: A situational approach to service evaluation. J Nurs Manag 2004; 12: 22-7. doi: 10.1111/j.13652834.2004.00389.x

33. Patton MQ. Qualitative evaluation and research methods. $2^{\text {nd }}$ ed. London: Sage Publications; 1990.

34. Berg BL. Qualitative research methods for the social scientists. $6^{\text {th }}$ ed. Boston, MA: Pearson Education, Inc; 2007.

35. Miller G, Dingwall R. Context and method in qualitative research. London: Sage; 1997.

36. Cohen L, Manion L, Morrison K. Research Methods in Education. $5^{\text {th }}$ ed. London and New York: Routledge; 2003.

37. Corbetta P. Social Research, Theory, Methods and Techniques. London: Sage; 2003.

38. Stewart DW, Shamdasani PN, Rook DW. Focus groups: Theory and practice. $2^{\text {nd }}$ ed. Thousand Oaks: Sage; 2007.

39. Mosadeghrad AM, Ferlie E, Rosenberg D. A study of relationship between job satisfaction, organisational commitment and turnover intention among hospital employees. Health Serv Manage Res 2008; 21: 211-27. doi: 10.1258/hsmr.2007.007015

40. Mosadeghrad AM, Ferlie E, Rosenberg D. A Study of relationship between job stress, quality of working life and turnover intention among hospital employees. Health Serv Manage Res 2011; 24: 170-81. doi: 10.1258/hsmr.2011.011009

41. Mosadeghrad AM, Yarmohammadian MH. A study of relationship between managers' leadership style and employees' job satisfaction. Int J Health Care Qual Assur Inc Leadersh Health Serv 2006; 19: xi-xxviii. doi: 10.1108/13660750610665008

42. Dehghan Nayeri N, Nazari AA, Salsali M, Ahmadi F, Adib Hajbaghery M. Iranian staff nurses' views of their productivity and management factors improving and impeding it: A qualitative study. Nurs Health Sci 2006; 8: 51-6. doi: 10.1111/j.14422018.2006.00254.x

43. Mohammad-Alizadeh $S$, Wahlström R, Vahidi R, Nikniaz $A$, Marions L, Johansson A. Barriers to high-quality primary reproductive health services in an urban area of Iran: views of public health providers. Midwifery 2009; 25: 721-30. doi: 10.1016/j.midw.2008.01.002

44. Zarea K, Negarandeh R, Dehghan-Nayeri N, Rezaei-Adaryani $M$. Nursing staff shortages and job satisfaction in Iran: Issues and challenges. Nurs Health Sci 2009; 11: 326-31. doi: 10.1111/j.1442-2018.2009.00466.x

45. Haas JS, Cook EF, Puopolo AL, Burstin HR, Cleary PD, Brennan TA. Is the professional satisfaction of general internists associated with patient satisfaction? J Gen Intern Med 2000; 15: 122-8. doi: 10.1046/j.1525-1497.2000.02219.x

46. DiMatteo MR, Sherbourne CD, Hays RD, Ordway L, Kravitz RL, McGlynn EA, et al. Physicians' characteristics influence patients' adherence to medical treatment: Results from the medical outcomes study. Health Psychol 1993; 12: 3-102. doi: 10.1037/0278-6133.12.2.93

47. Mosadeghrad AM, Ferdosi M. Leadership, job satisfaction and organizational commitment in healthcare sector: Proposing and testing a model. Mat Soc Med 2013; 25: 121-6. doi: 10.5455/ msm.2013.25.121-126

48. Freund A. Commitment and job satisfaction as predictors of turnover intentions among welfare workers. Adm Soc Work 2005; 29: 5-21. doi: 10.1300/j147v29n02_02

49. Hong SC, Goo YJJ. A causal model of customer loyalty in professional service firms: an empirical study. International Journal of Management 2004; 21: 531-41.

50. Sit WY, Ooi KB, Lin B, Chong AYL. TQM and customer satisfaction 
in Malaysia's service sector. Industrial Management \& Data Systems 2009; 109: 957-75. doi: 10.1108/02635570910982300

51. Yang CC. The impact of human resource management practices on the implementation of total quality management: An empirical study on high-tech firms. The TQM Journal 2006; 18: 162-73. doi: 10.1108/09544780610647874

52. Mosadeghrad AM. Why TQM programs fail? A pathology approach. The TQM Journal 2014; 26: 160-87. doi: 10.1108/ tqm-12-2010-0041

53. Mosadeghrad AM. Why TQM does not work in healthcare organisations. Int J Health Care Qual Assur 2014; 27: 320-35. doi: $\quad 10.1108 /$ ijhcqa-11-2012-0110

54. Mosadeghrad AM. Obstacles to TQM success in health care systems. Int J Health Care Qual Assur 26: 147-73. doi: 10.1108/09526861311297352

55. Putnam RD. Tuning in, tuning out: The strange disappearance of social capital in America. Political Science and Politics 1995; 28. 664-83. doi: 10.1017/s1049096500058856

56. Mosadeghrad AM. Essentials of Total Quality Management in Healthcare: A systematic review. Int J Health Care Qual Assur 2014; 27: 544-58. doi: 10.1108/ijhcqa-07-2013-0082

57. Joolaee S, Mehrdad N. An investigation on patients' awareness of their own rights. In Proceedings of 3rd National Congress of
Bioethics. June 25-28 2003, Bursa, Turkey. pp. 517-24

58. Mosadeghrad AM. Esnaashary P. [A study of relationship between patients' knowledge about patients' rights and their satisfaction]. Teb and Tazkieh 2005;14: 16-24.

59. Mosadeghrad AM, Ferdosi M, Afshar H, Hosseini-Nejhad M. The impact of top management turnover on quality management implementation. Med Arch 2013; 67: 134-40. doi: 10.5455/ medarh.2013.67.134-140

60. Elsey B, Eskandari M. Identifying the management development needs of senior executives in Iran's teaching hospitals. $J$ Manag Med 1999; 13: 421-35. doi: 10.1108/02689239910371208

61. Mohammadi M, Mohammadi F, Zohrabi M. Quality management in Iran: Past experience, attitudes, and challenges. Proceedings of the $10^{\text {th }}$ world congress for TQM. 2005, University of Manitoba, Canada.

62. Glickman SW, Baggett KA, Krubert CG, Peterson ED. Promoting quality: The health-care organization from a management perspective. Int J Qual Health Care 2007; 19: 341-8. doi: 10.1093/intqhc/mzm047

63. Osland J, Kolb D, Rubin I. Organizational behaviour: An experiential approach. $7^{\text {th }}$ ed. Upper Saddle River, NJ: Prentice Hall; 2000.

\section{Key Messages}

Implications for policy makers

- Healthcare service providers are encouraged to regularly monitor healthcare quality and accordingly initiate continuous quality improvement programmes to maintain high levels of patient satisfaction.

- Healthcare quality can be improved by supportive leadership, proper planning, education and training, and effective management of resources, employees, and processes. Healthcare managers should apply techniques and tools to operationalise these quality management constructs. Policy-makers' support, in terms of providing necessary resources and establishing supportive rules and regulations is critical.
Implications for public

Patients are constantly looking for quality healthcare services. Understanding the factors that affect healthcare service quality helps benchmark for best practices, deliver appropriate care, and improve processes to reduce the frequency and severity of medical errors. 